\title{
Effect of Functionalities of Binders on Rheological Behavior of Alumina Suspensions and Properties of Green Sheets
}

\author{
Koichi NAGATA \\ Central Research Laboratory, Kyocera Corporation, 1-4, Yamashita-cho, Kokubu-shi, Kagoshima \\ $899-43$
}

\begin{abstract}
バインダーの極性基数が懸濁液のレオロジカルな性質, グリーンシート特性に及ぼす影響 永田公一

京セラ(株)総合研究所, 899-43 鹿児島県国分市山下町 1-4
\end{abstract}

[Received August 24, 1992; Accepted May 21, 1993]

\begin{abstract}
The effect of functionalities of acrylic binders on rheological behavior of aqueous alumina suspensions and properties of green sheets was investigated to find optimal conditions for the tape casting process. The funetionalities of binders were 35,20 and $10 \mathrm{mg} \mathrm{KOH} / \mathrm{g}$. These binders had almost the same glass transition points $\left(T_{\mathrm{g}}\right)$ and molecular weights $\left(M_{\mathrm{w}}\right)$. Suspensions containing binders with low functionalities showed high shear-thinning flow behavior and high yield stresses. The resultant green sheets had low packing densities, low strengths and small elongations. In contrast, suspensions containing binders with high functionalities showed low shear-thinning flow behavior and low yield stresses. Suspensions gave green sheets with high packing densities, high strengths and large elongations in this case. As functionalities of binders increased, the amounts of adsorbed binders on alumina particles decreased and solubilities of binder sheets in aqueous solutions increased. It is found that the dispersibility of suspension is controlled by adsorption of binder on alumina particles and binder solubility in aqueous solution. It is also found that the strength of green sheet is determined by that of binder sheet. The results are interpreted as follows; increase in functionality enhances the cross-linking of chain molecules in the binder by forming hydrogen bonds between carboxylic acid sites.
\end{abstract}

Key-words : Alumina, Binder, Functionality, Suspension, Green sheet, Rheological behavior

\section{Introduction}

While suspensions containing nonaqueous binders are effectively used in ceramic tape casting process, suspensions with water-soluble binders have not been widely used. Since the aqueous system has advantages of incombustibility, non-poison and low cost, suspension with aqueous binders should be more used for fabrication of green sheets.

Nahass et al.1),2) proposed the use of latex binder system to obtain a high binder content necessary for high mechanical strength of the green sheet while maintaining low viscosity of the suspension. However, use of the latex binder tends to make the obtained green sheet insoluble in water so that this gives green sheet with a difficulty for recycling. Elucidation of characteristics of water-soluble binders and suspensions is important for employment of aqueous green sheets.

Flocculation of oxide particles in a suspension is induced by the van der Waals force between particles. Two possible mechanisms are considered for dispersing powders, electrical stabilization or steric stabilization. ${ }^{3}{ }^{4)}$ Kitahara et al.5) interpreted that the dispersion of particles based on binder adsorption is caused by steric stabilization.

The molecular structure of aqueous binders has many hydrophilic ionic groups along the polymer chains. Carboxylic acid groups are typical in hydrophilic ionic groups. In the case where carboxylic acid groups are used as hydrophilic agent in aqueous binders, properties of alumina green sheet are controlled by the $\mathrm{pH}$ of suspension, as reported in our previous works. ${ }^{6)}$,7) However, the effect of a number of carboxylic groups, i.e., functionalities, of binders on the rheological behavior of suspension and properties of green sheets have not clarified yet.

The work was planned to clarify the details of the effect of functionalities of binders on properties of the alumina suspensions and green sheets. The relationship between the amount of adsorbed binders and solubility of binders in the solutions was studied in order to obtain good dispersion.

\section{Experimental procedure}

\subsection{Materials}

The alumina powder used in this study was AL160 SG (Showa Denko K. K.) with an average particle size of $0.6 \mu \mathrm{m}$ as measured by the microtrac technique and a surface area of $6.0 \mathrm{~m}^{2} / \mathrm{g}$ as measured by the standard BET $\mathrm{N}_{2}$ adsorption technique. The zero point of charge of alumina powder was at approximately $\mathrm{pH} 8.0$ determined by electrophoretic mobility measurement.

Used binders (P-1, P-2 and P-3, Lion Co., Ltd.) were co-polymers with the same segments of acrylic esters and various functionality of acrylic acid. Binders have almost the same $T_{\mathrm{g}}$ and $M_{\mathrm{w}}$. Properties of the binders are shown in Table 1. Binder solutions of 
Table 1. Properties of binders.

\begin{tabular}{|c|c|c|c|}
\hline & $\begin{array}{c}\text { Molecular } \\
\text { Weight } \\
\left(\mathrm{x}^{4} \mathrm{O}^{4}\right)\end{array}$ & $\begin{array}{c}\mathrm{Tg} \\
\left({ }^{\circ} \mathrm{C}\right)\end{array}$ & $\begin{array}{c}\text { Functionality } \\
\left(\mathrm{mg}_{\mathrm{g} O H} / \mathrm{g}\right)\end{array}$ \\
\hline $\mathrm{P}-1$ & 7.1 & -17.0 & 35 \\
\hline $\mathrm{P}-2$ & 7.4 & -18.0 & 20 \\
\hline $\mathrm{P}-3$ & 8.1 & -18.4 & 10 \\
\hline
\end{tabular}

$\mathrm{pH}=8.5$ were prepared by adding $\mathrm{NH}_{3}$ solution to the binders. The titration results showed that at $\mathrm{pH}$ values $\geqq 8.0$ the binder is negative and saturated with $\alpha$ (the fraction dissociated) approaching 1 .

$500 \mathrm{~g}$ of alumina powder, $150 \mathrm{~g}$ of distilled water of $\mathrm{pH}=7.5$ and $150 \mathrm{~g}$ of binder solutions were mixed using $500 \mathrm{~g}$ of alumina balls for $20 \mathrm{~h}$ by ball milling. Properties of binder solutions and suspensions are shown in Table 2.

Alumina suspensions were cast on a poly (ethylene terephthalate) film by a doctor blade technique and air dried at $80^{\circ} \mathrm{C}$ for $1 \mathrm{~h}$. The thickness of obtained green sheets were about $600 \mu \mathrm{m}$. Green sheets with low packing densities were prepared by increasing water contents in the suspensions in order to find relationship between the strengths and packing densities of green sheets.

\subsection{Measurements}

The functionality of binder is the weight $(\mathrm{mg})$ of $\mathrm{KOH}$ necessary to neutralize $1 \mathrm{~g}$ of binder. This functionality was determined by titration with $0.1 \mathrm{~N}$ $\mathrm{KOH}$ solution, where Thymol blue in dimethylformaldehyde solutions was used as a reagent. Carboxylic acid groups are dissociated to $-\mathrm{COO}^{-}$.

$M_{\mathrm{w}}$ of binders were determined in THF by gel permeation chromatography. $T_{\mathrm{g}}$ of binders were calculated by the weight ratio and $T_{\mathrm{g}}$ of each homopolymer.

Viscosity was measured with a rotary viscometer (Tokyo Keiki Co., Ltd.). TI value is the ratio of viscosities at shear rates of $5 \mathrm{~s}^{-1}$ and $50 \mathrm{~s}^{-1}$ taken as an index of flow behavior of the suspension. The TI value of unity means the ideal Newtonian flow behavior and a TI value higher than unity means shearthinning flow behavior. The yield stress of suspension is calculated by Casson's equation (1).

$$
\sqrt{S}=a \sqrt{D}+\sqrt{S_{0}}
$$

where $S$ is stress $(\mathrm{Pa}), D$ is shear rate $\left(\mathrm{s}^{-1}\right), S_{0}$ is yield stress $(\mathrm{Pa})$ and $a$ is a constant.

The strengths and elongations of green sheets as well as binder sheets were determined by an Instrontype machine with a crosshead speed of $500 \mathrm{~mm} /$ min. Binder sheets were prepared by casting and drying binder solutions at $80^{\circ} \mathrm{C}$ for $1 \mathrm{~h}$.

$100 \mathrm{~g}$ of alumina powder was mixed with $100 \mathrm{~g}$ of various concentrations of binder solutions for $20 \mathrm{~h}$. After the suspensions were separated by a centrifuge at $10000 \mathrm{rpm}$ for $1 \mathrm{~h}$, the binder adsorption were determined by weighing the content in superna-
Table 2. Properties of binder solutions and suspensions.

\begin{tabular}{|c|c|c|c|c|c|c|}
\hline & \multicolumn{3}{|c|}{ Binder solutions } & \multicolumn{3}{|c|}{ Suspensions } \\
\cline { 2 - 7 } & $\mathrm{pH}$ & $\begin{array}{c}\text { Solid } \\
\text { content } \\
(\text { wty })\end{array}$ & $\begin{array}{c}\text { Viscosity } \\
\text { (cps) }\end{array}$ & $\mathrm{pH}$ & $\begin{array}{r}\text { Yield } \\
\text { stress } \\
\text { (Pa) }\end{array}$ & $\begin{array}{c}\text { Relative } \\
\text { Viscosity }\end{array}$ \\
\hline $\mathrm{P}-1$ & 8.5 & 25 & 1000 & 8.8 & 0.32 & 1.25 \\
\hline $\mathrm{P}-2$ & 8.5 & 25 & 750 & 8.8 & 0.64 & 3.01 \\
\hline $\mathrm{P}-3$ & 8.5 & 25 & 500 & 8.8 & 0.97 & 20.5 \\
\hline
\end{tabular}

tent solutions.

The solubility of binder sheets was measured by agitating $0.5 \mathrm{~g}$ of the binder sheets in $50 \mathrm{~g}$ of various $\mathrm{pH}$ of $\mathrm{NH}_{3}$ solutions for $1 \mathrm{~h}$ by a magnetic stirrer.

\section{Results and discussion}

Relations between viscosity of suspension versus shear rate are shown in Fig. 1 for three binders. These viscosity data were determined with usual technique increasing shear rate. The suspension P-3 containing a binder of functionality $=10$ exhibits the highest viscosity over the range of used shear rates, while the viscosity of binder solution is the lowest in this case. The suspension $\mathrm{P}-1$ containing a binder of functionality $=35$ exhibits a shear-rate dependence similar to that of the suspension P-3. However, the viscosity of suspension $\mathrm{P}-1$ is always lower than that of the suspension $\mathrm{P}-3$ at each shear rate. Table 2 shows $\mathrm{pH}$ and yield stresses measured for three suspensions. As the functionality of binder decreases, the yield stress increases. The observation of high shear-thinning flow behavior, high relative viscosity $\left(\eta_{\text {relative }}=\eta_{\text {suspension }} / \eta_{\text {liquid }}\right)$ and high yield stress indicate that the suspension P-3 is poorly dispersed. In contrast, well dispersibility is indicated by low shearthinning flow behavior, low relative viscosity and low yield stress in the suspension P-1. Shear-thinning flow behavior results from the breakdown of the flocculated structure. High shear-thinning flow and high yield stress value indicate that binder-bridging flocculation occurs in the suspension $\mathrm{P}-3$. The results imply that the apparent strength of flocculated structure is controlled by the functionality of the

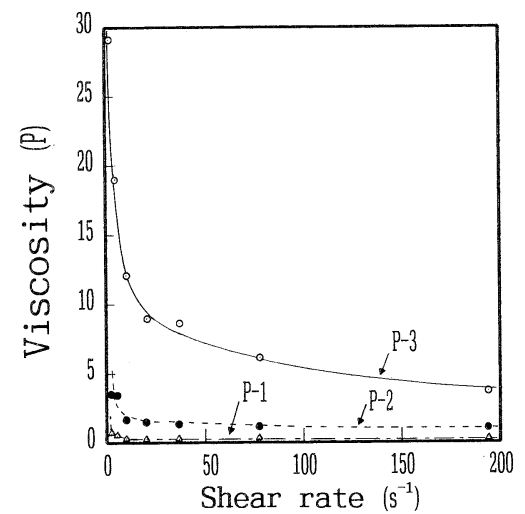

Fig. 1. Viscosity and shear rate of suspensions. 
binder used in the suspension. A similar functionality dependence was seen for the dispersibility of suspension containing dispersant in the previous work. . $^{8}$

Figure 2 shows TI values of suspensions versus packing densities of resultant green sheets as a function of functionalities of binders. As the functionality of binder decreases, the TI value of suspension increases and the packing density of resultant green sheet decreases. These results indicate that low packing density of the green sheet is caused by this flocculated structures and that the flocculated structures remain unbroken during the drying process. As $\mathrm{pH}$ value of the alumina suspension increased, the degree of shear-thinning of suspension and the packing density of resultant sheet decreased. A similar relation between the shear-thinning flow behavior and the low packing density of green sheet was observed in the previous work, ${ }^{7}$ where $\mathrm{P}-1$ was used as a binder and AL-45-1 as an alumina powder.

Figure 3 shows the equilibrium concentration of binder versus adsorbed amount on alumina particles at $\mathrm{pH}$ 8.8. The adsorption isotherms of these binders are of Langmuir type or high-affinity type. As the bin-

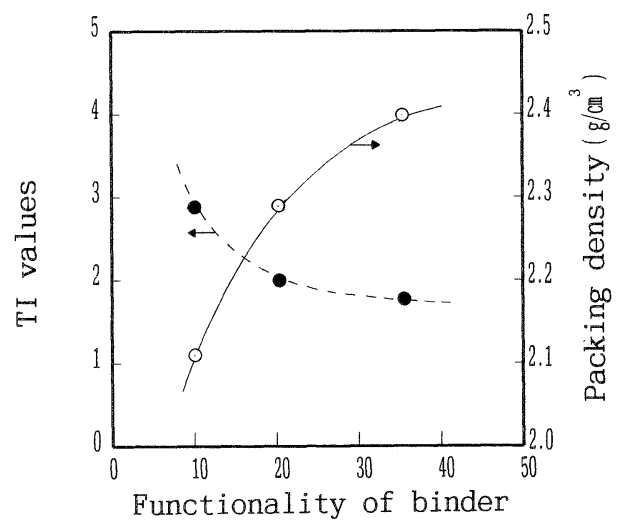

Fig. 2. TI values and packing density of green sheet as a function of functionality of binder.

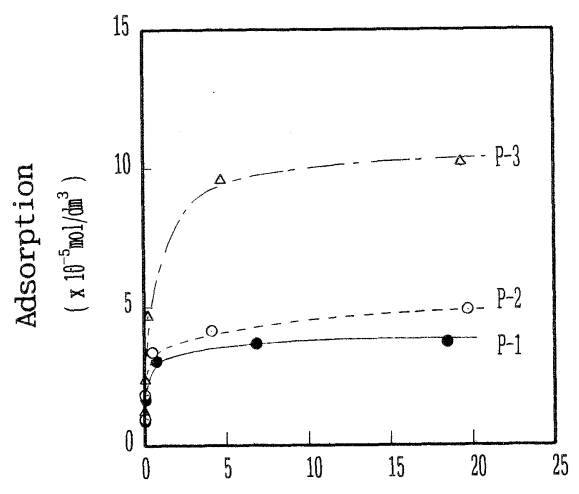

Equilibrium concentration $\left(x 10^{-5} \mathrm{~mol} / \mathrm{dm}^{3}\right)$

Fig. 3. Equilibrium concentration and adsorption of binder on alumina particles. der concentration increases, the particle surface becomes saturated with adsorbed binder and amounts of binder that remain in solution increase. The suspension containing the binder with highest functionality gives the lowest adsorption on alumina particles. Under the condition at $\mathrm{pH} 8.8$, the surface charge for this alumina particle is slightly negative and binder is negatively charged with $\alpha$ approaching 1. The electrostatic repulsive forces may occur between alumina particles and binder molecules.

Goodness of solvent for the binder is an important factor in steric stabilization as well as the good coverage of the particle surfaces with the adsorbed binder. In good solvent binder molecules are solvated and in the large expanded form. Solubilities of binder sheets to various pH's of $\mathrm{NH}_{3}$ solutions are shown in Table 3. As the functionality of binder decreases, the solubility to the $\mathrm{pH}<7.5$ water decreases. The binder sheet with low functionality is dissolved only in high-pH solution. Since the $\mathrm{pH}$ of water used in this study is 7.5 , this binder sheet does not dissolve in it. These results imply that the $\mathrm{pH}=7.5$ water is a poor solvent to the binder with low functionality and that this binder is more stable in the adsorbed state on the alumina particles than remaining free in the solution. ${ }^{9)}$ In poor solvent, binder is insoluble and binder molecule chains tend to coagulate. It is considered that the main reason why the steric stabilization of suspension is weak is that good 'train-loop-tail' adsorption layers on the surface of alumina particles are not formed by coagulated binder molecules. In this case, the poor dispersibility with high yield stress and high shear-thinning flow behavior of suspension is understood to be caused by lack of steric stabilization. In contrast, the $\mathrm{pH}=7.5$ water is a good solvent for the binder with high functionality. The binder adsorbed on alumina particles may be in a good 'train-loop-tail' form so that the steric stabilization of the suspension is strong. ${ }^{3)}$

Figure 4 shows the functionality of binder versus the strength and elongation. As the functionality of binder increases, the strength and elongation increase. In order to clarify the relationship between the strengths and packing densities of the green sheets, green sheets with various packing densities were prepared by changing water contents in the suspension.

Figure 5 shows the packing density versus water content in the suspension. As the water content in

Table 3. Solubility of binder sheets.

\begin{tabular}{|c|c|c|}
\hline & $\begin{array}{c}\text { Functionality } \\
\text { (mgKOH/g) }\end{array}$ & $\begin{array}{l}\text { Solubility in dil. } \mathrm{NH}_{3} \\
\text { aqueous solution } \\
7.0 \quad 7.5 \quad 8.0 \quad 8.5 \quad 9.0\end{array}$ \\
\hline $\mathrm{P}-1$ & 35 & $\begin{array}{lllll}0 & 0 & 0 & 0 & 0 \\
\end{array}$ \\
\hline $\mathrm{P}-2$ & 20 & $\begin{array}{lllll}x & 0 & 0 & 0 & 0 \\
\end{array}$ \\
\hline $\mathrm{P}-3$ & 10 & $\begin{array}{lllll}x & x & 0 & 0 & 0\end{array}$ \\
\hline
\end{tabular}




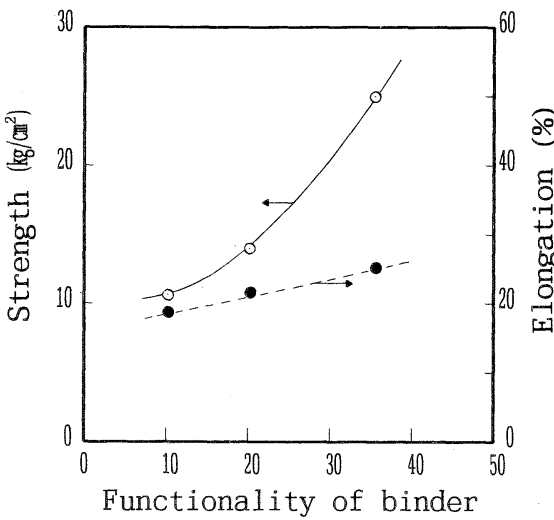

Fig. 4

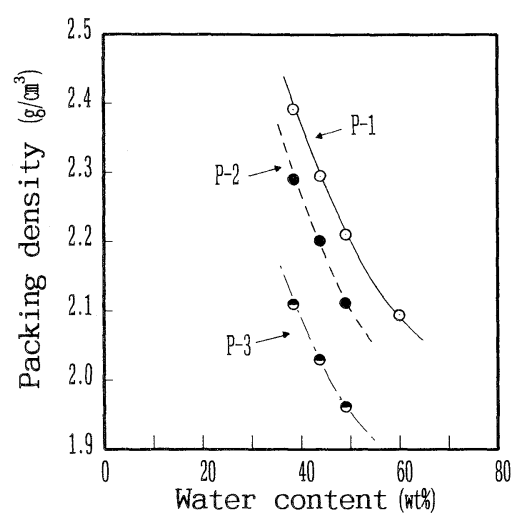

Fig. 5

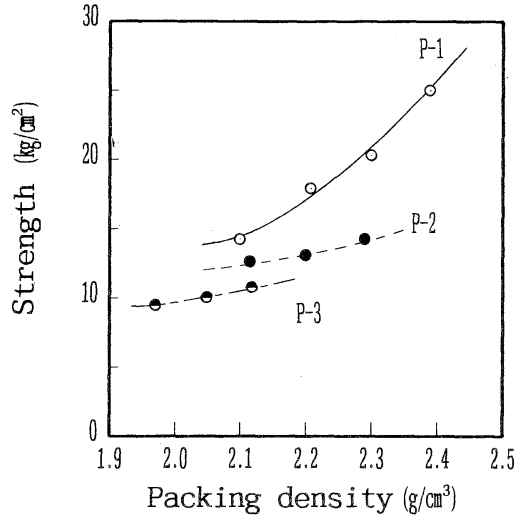

Fig. 6

Fig. 4. Strength and elongation of green sheets as a function of functionality of binder.

Fig. 5. Packing density of green sheet and water content of suspensions.

Fig. 6. Strength and packing density of green sheet.

the suspension increases, the packing density of green sheet decreases. This is expected because amount of binder molecules is lacking in maintaining a stable suspension at higher water content.

Figure 6 shows the packing density versus the strength of green sheet. As the functionalities of binders increase, the strengths of green sheets increase when the strengths of green sheets are compared at the same packing density $=2.10 \mathrm{~g} / \mathrm{cm}^{3}$. Assuming that distances between alumina particles are equal in the green sheet with the same packing density, the strength of green sheet should be determined by the strength of the binder sheet.

Figure 7 shows the strengths of binder sheets as a function of the functionalities of binders. The elongation of binder sheets are more than $8000 \%$ without breaking points. The strength of binder sheets increase with increase of functionalities of binders, though three binders have almost the same $T_{\mathrm{g}}$ and $M_{\mathrm{w}}$. Molecules of acrylic resin are in the chain form, which is easily changed into round form by microbrownian motion. The force between molecules is generally so weak that the resistance against movement of molecules is small. Chain molecules with a

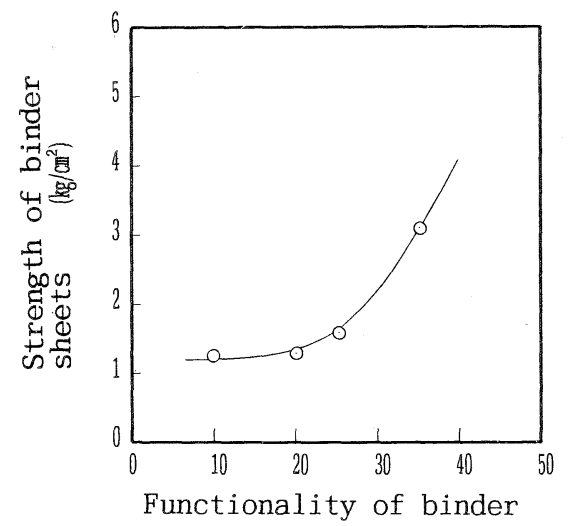

Fig. 7. Strength of binder sheets as a function of functionality of binder. large number of carboxylic acid sites, however, are cross-linked by hydrogen bonding between carboxylic acid sites. Micro-brownian motion restricted by cross-linking of chain molecules enhances the strength of resultant binder sheet. In contrast, the binder with low functionality has a small number of carboxylic acid sites and less cross-linking, so that the strength of green sheet is low.

The results imply that the properties of binder sheets determine the strength and elongation of the resultant green sheets.

\section{Conclusions}

The effect of functionalities of binders on rheological behavior of suspensions and properties of obtained alumina green sheets was investigated to find optimal conditions for the tape casting process. The results are summarized as follows.

(1) Suspensions containing binders of functionality $=10$ showed high shear-thinning flow behavior and high yield stresses. Suspensions gave the resultant green sheets with a low packing densities, low strengths and small elongation in this case. In contrast, suspensions containing binders of functionality $=35$ showed low shear-thinning flow behavior and low yield stresses. Resultant green sheets had high packing densities, high strengths and large elongations in this case.

(2) The adsorption of binder on alumina particles was high in suspensions containing binders of functionality $=10$. The obtained binder sheet showed a low solubility to the $\mathrm{pH}<7.5$ water. These results indicate that the low-solubility binder is more stable in the adsorbed state on alumina particles than remaining free in the solution. In poor solvent, binder molecules tend to coagulate. In this case, good 'train-loop-tail' adsorption layers are not formed by coagulated binder molecules so that the steric stabilization of suspension is weak. The shear-thinning flow behavior of the suspension containing low func- 
tionality of binder is understood to be caused by lack of steric stabilization. In contrast, the amount of adsorbed binders on alumina particles is small in the functionality $=35$ suspensions. The obtained binder sheet showed a high solubility to the $\mathrm{pH}<7.5$ water. From these results the binder adsorbed on alumina particles may be in a good 'train-loop-tail' form and steric stabilization of suspension is strong in this case.

(3) As the functionality of binder increased, the strength of green sheet increased. It is found that the strengths of green sheet are determined by the strengths of binder sheets. As the functionality increases, the binder chains are cross-linked by hydrogen bonding between carboxylic acid sites so that the strength of binder sheet increases.

Acknowlegements The author is grateful to Lion Corp., Chemical Laboratory for technical assistance.
(This work was reported in the 1992 Annual Meeting of The Ceramic Society of Japan, Proceeding (1992) p. 183.)

\section{References}

1) P. Nahass, W. E. Rhine, R. L. Pober, H. K. Bowen and W. L. Robbins, "Ceramic Transactions, Vol. 15", Ed. by K. M. Nair, R. Pohanka and R. C. Buchanan, Am. Ceram. Soc., Westerville, Ohio (1990) pp. 355-64.

2) N. Ushifusa and M. J. Cima, J. Am. Ceram. Soc., 74, 2443-47 (1991).

3) D. H. Napper, J. Colloid Interface Sci., 58, 390-407 (1977).

4) M. J. Void, J. Colloid Sci., 16, 1-12 (1961).

5) F. Kitahara, K. Furusawa, "Bunsan, Nyukakei no Kagaku", Kogakutosho (1979) p. 77.

6) K. Nagata, "Ceramic Powder Science N", Ed. by S. Hirano, G. L. Messing and H. Hausner, Am. Ceram. Soc., Westerville, Ohio (1992) pp. 335-40.

7) K. Nagata, "Forming and Technology for Ceramics", Ed. by M. J. Cima, Am. Ceram. Soc., Westerville, Ohio (1992) pp. 205-10.

8) K. Nagata, Proceedings of Fall Meeting of the Ceramic Society of Japan, October 15-18 (1991) p. 371.

9) A. Takahasi, Shikizai, 59, 168-75 (1986). 